\title{
Optimizing the yield of transient mono-dimethyl disulfide adducts for elucidating double
}

bond positions of long chain alkenones

Nora Richter, ${ }^{\mathrm{a}}$ James T. Dillon, ${ }^{\mathrm{a}}$ Derek M. Rott, ${ }^{\mathrm{b}}$ Michael A. Lomazzo, ${ }^{\mathrm{b}}$ Christopher T. Seto, ${ }^{\mathrm{b}}$ Yongsong Huang ${ }^{\mathrm{a}}$

${ }^{a}$ Department of Earth, Environmental and Planetary Sciences, Brown University, Providence, RI 02912, USA

${ }^{\mathrm{b}}$ Department of Chemistry, Brown University, Providence, RI 02912, USA

*Corresponding Author: Yongsong Huang

Email: yongsong_huang@brown.edu

Phone: +1 (401) 863-3822

Fax: +1 (401) 863-2058 


\section{Abstract}

Long chain alkenones (LCAs) are among the most successful biomarkers for paleotemperature reconstructions. However, fundamental questions regarding the biosynthesis and cellular functions of alkenones in haptophyte algae remain poorly understood. Recent discoveries of LCAs with double bond positions and chain lengths that differ from common structures further highlight the importance of continued research into structural variations of this important class of lipid biomarkers to improve LCA applications as temperature proxies. Double bond positions on alkyl chains can be effectively determined by preparing mono-double bond adducts with dimethyl disulfide (DMDS-1), and subsequent gas chromatography-mass spectrometry (GC-MS) analysis. However, previously published procedures for adduct preparation were originally designed for mono-unsaturated fatty acids, and generally produce low product yields when applied to alkenones. Here we demonstrate that the problem originates mainly from DMDS and alkenone overreaction at high temperatures and for long time periods, and, secondarily, insufficient amount of iodine catalyst. The overreaction results in DMDS reacting with multiple double bonds, and the possible formation of intermolecular linkages, creating non-volatile products. These products are of little use for elucidating alkenone structures. We demonstrate that by reducing the reaction temperature and time, and by using an optimal amount of iodine, we can maximize the yield of transient DMDS-1 adducts for alkenone structure determination.

\section{Keywords:}

Dimethyl disulfide; alkenone; double bond; structure characterization; derivatization 


\section{Introduction}

Long chain alkenones (LCAs) are a class of unsaturated methyl and ethyl ketones produced by specific haptophyte algae in the ocean and terrestrial aquatic environments across the globe (de Leeuw et al., 1980; Volkman et al., 1980; Brassell et al., 1986; Zink et al., 2001; Longo et al., 2016). The number of LCA double bonds respond linearly to growth temperatures between 5-25 ${ }^{\circ} \mathrm{C}$ (Prahl and Wakeham, 1987; Prahl et al., 1988; Conte et al., 1998), yet they exhibit a nonlinear response at more extreme temperatures (Prahl et al., 1988; Conte et al., 1998). LCAs have been successfully applied to paleotemperature reconstructions in marine environments for the past four decades (Brassell et al., 1986; Prahl and Wakeham, 1987; Prahl et al., 1988; Müller et al., 1997; Herbert, 2006). Recently major efforts have been made to apply alkenone temperature proxies in lacustrine and estuarine systems; however, these systems are generally more complex. Lakes and estuaries generally harbor a more diverse group of alkenoneproducing haptophytes, complicating temperature calibrations (Theroux et al., 2010). Studies are revealing that haptophytes in these environments produce a wider range of alkenones with variations in double bond positions (Rontani et al., 2006; Longo et al., 2013; Dillon et al., 2016), the degree of unsaturation (Jaraula et al., 2010), and chain lengths (Xu et al., 2001; Prahl et al., 2006; van Soelen et al., 2014; Zhao et al., 2014) in response to various environmental parameters (Prahl et al., 2006) or post-depositional changes (Rontani et al., 2006). Longo et al. (2016) proposed that temporal variations in salinity levels could favor certain species at a given time, indicating the need for a more in-depth understanding of alkenone production under different environmental conditions. 
To further improve alkenone paleothermometery in both lacustrine and marine environments, convenient and reproducible methods are needed to identify double bond positions for alkenones. Double bond positions in alkenones can be determined through osmium tetroxide $\left(\mathrm{OsO}_{4}\right)$ oxidation followed by the addition of trimethylsilyloxy groups (de Leeuw et al., 1980; Rontani et al., 2001, 2006) or through imine derivatization of the ketone (López and Grimalt, 2006), followed by gas chromatography-mass spectrometry (GC-MS) analyses. Comparisons to analytical standards indicate that alkenone double bonds mainly occur in the trans configuration (Rechka and Maxwell, 1988), but have also been found as cis/trans or trans/cis isomers resulting presumably from the action of extracellular bacterial isomerases during the diagenesis stage (Rontani et al., 2005). However, the formation of the trimethylsilyloxy derivatives requires a substantial addition of molecular mass to each double bond and increases the boiling point of the final product, which has limited this method to alkenones with maximal two double bonds (Zheng et al., 2015). Imine derivatization of the alkenone carbonyl group produces useful fragments for double bond position identification (López and Grimalt, 2004, 2006), but also yields additional mass fragments and sometimes non-unique assignments of double bond positions (López and Grimalt, 2004, 2006; Zheng et al., 2015).

We recently reported double bond positions of tri-unsaturated alkenone isomers (Dillon et al., 2016; Zheng et al., 2016) by imine derivatization of the alkenone carbonyl group and dimethyl disulfide (DMDS) double bond adduction, using a new gas chromatographic separation method that provides higher selectivity of derivatized alkenones than conventional methods (Longo et al., 2013). In contrast to the $\mathrm{OsO}_{4}$ oxidation method (de Leeuw et al., 1980; Rontani et al., 2001, 2006), DMDS can separately and consecutively bind to individual double bonds in an alkenone molecule (termed DMDS-1), creating products with distinct mass fragments at any 
given double bond position without significantly decreasing the product volatility (Buser et al., 1983; Dillon et al., 2016). To account for fragments that are structurally symmetric (i.e., ions which may be assigned to two different double bond positions on opposite sides of the alkyl chain based on the mass spectra for DMDS adducts), compounds can be further derivatized using cyclobutylimine to arrive at a structurally unique solution (Zheng et al., 2016).

Despite our initial success (Longo et al., 2013; Dillon et al., 2016; Zheng et al., 2016), there are major problems with published procedures for alkenone DMDS adduction. In our experience, applying published DMDS adduction procedures (Francis, 1981; Leonhardt and DeVilbiss, 1985; Yamamoto et al., 1991; Xu et al., 2001; van Soelen et al., 2014; Zhao et al., 2014) to alkenones, has frequently resulted in the lack of alkenone adducts in GC-MS analyses and even the complete absence of the original alkenones (i.e., total sample loss). Discussions with experienced alkenone researchers confirm similar experiences with DMDS derivatization (Maureen Conte, personal communication, April 8, 2015). Notably, the DMDS derivatization method was originally designed for mono-unsaturated fatty acids (reviewed by Christie, 1998). In the case of di-unsaturated and tri-unsaturated, methylene-interrupted fatty acids (with one, two, or three methylene interruptions), the products often contain cyclized sulfur products, making the interpretation of double bond positions difficult or impossible (Vincenti et al., 1987; Pepe et al., 1997; Méjanelle et al., 2002). Numerous studies using the DMDS derivatization method have tried to modify the procedure. In general, the experiments still involve heating at temperatures ranging from room temperature to $70{ }^{\circ} \mathrm{C}$ for 30 mins to 24 hours (Francis, 1981; Buser et al., 1983; Leonhardt and DeVilbiss, 1985; Shibahara et al., 1985; Vincenti et al., 1987; Yamamoto et al., 1991; Pepe et al., 1997; Xu et al., 2001; Méjanelle et al., 2002; Shibahara et al., 2008; van Soelen et al., 2014; Zhao et al., 2014; Dillon et al., 2016; Zheng et al., 2016). In all of 
the reactions iodine is used as a catalyst, however, the amount of iodine added varies from 0.1$4.0 \mathrm{mg}$ of $\mathrm{I}_{2}$ (Francis, 1981; Buser et al., 1983; Leonhardt and DeVilbiss, 1985; Vincenti et al., 1987; Yamamoto et al., 1991; Xu et al., 2001; Shibahara et al., 2008). Further complications arise when applying these procedures to alkenones. For instance, alkenones can have up to five double bonds (Jaraula et al., 2010), such that if DMDS is bonded to all double bond positions, the molecular weight of the product is too high for conventional GC-MS analysis.

Obtaining derivatives with DMDS mono-adducts can aid in structure identification. Yamamoto et al. (1991) recognized the significance of DMDS mono-adducts when applying this method to fatty acids. The reaction was performed at a lower temperature $\left(35^{\circ} \mathrm{C}\right)$ and for a shorter time (30 mins) to obtain mono-adducted dienoic esters (Yamamoto et al., 1996), yet it remains unclear how product yield changes under varying temperature and catalyst conditions. This methodology was recognized and applied to some fatty acid studies (Carballeira et al., 1994; Urbanová et al., 2004), however, it did not become a commonly accepted method for fatty acids. There were also no reports on an optimized method for obtaining DMDS mono-adducts. DMDS adduction was also applied to alkenones for structure elucidation (Zhao et al., 2014; Dillon et al., 2016; Zheng et al., 2016); but most alkenone studies used long reaction times and high temperatures to generate DMDS adducts where all the alkenone double bonds were derivatized (Xu et al., 2001; Méjanelle et al., 2002; van Soelen et al., 2014).

In our recent studies, we were occasionally successful at obtaining visible, but low, DMDS-1 adducts after multiple attempts at derivatizing alkenones (Zhao et al., 2014; Dillon et al., 2016; Zheng et al., 2016). The difficulty in obtaining a consistent and reasonable DMDS-1 yield could be a result of mono-DMDS adducts being transient products, such that the yields are very sensitive to reaction conditions and duration. In this study, we seek to address this problem. 
Taking advantage of the exceptionally high alkenone abundance in Lake BrayaS $\varnothing$, Greenland, we are able to perform repeated experiments under systematically varied reaction conditions. The overall objective is to improve DMDS addition to alkenone double bonds by identifying optimal reaction conditions that maximize product yield with reproducible results. 


\section{Experimental}

\subsection{Reagents}

All solvents were HPLC grade from Fisher Scientific (USA). Diethyl ether $\left(\mathrm{Et}_{2} \mathrm{O}\right.$, > 99\%), dimethyl disulfide (> 98\%), iodine (> 99.8\%), sodium thiosulfate (> 99\%) and sodium sulfate (anhydrous, > 99\%) were purchased from Sigma Aldrich (USA).

\subsection{Sample preparation}

Alkenone samples used for the DMDS optimization reactions were extracted from sediments retrieved from Lake BrayaSø, western Greenland, which is known for its extremely high alkenone concentrations (D'Andrea and Huang, 2005). Sediment samples were freeze-dried and homogenized, prior to extraction using dicholormethane/methanol (DCM/MeOH; 9:1, v/v) with an Accelerated Solvent Extractor ASE200 (Dionex) at $120^{\circ} \mathrm{C}$ and 1200 psi. Solvent extracts were separated into acid and neutral fractions by flash chromatography $\left(\mathrm{LC}-\mathrm{NH}_{2}, 40-63\right.$ $\mu \mathrm{m})$ using $4 \%$ acetic acid in diethyl ether to elute the acid fraction and DCM/isopropanol (2:1, $\mathrm{v} / \mathrm{v}$ ) to extract the neutral fraction. The neutral fraction was evaporated to dryness with nitrogen, and then re-dissolved in hexane. The resulting solution was separated via flash chromatography ( $\mathrm{SiO}_{2}, 40-63 \mu \mathrm{m}$ ) yielding hexane (alkane), DCM (ketone), and methanol (alcohol) fractions. The ketone fraction, which contains alkenones, was evaporated to dryness, and re-dissolved in hexane for quantification using gas chromatography-flame ionization detection (GC-FID). 


\subsection{Preparation of alkenone dimethyl disulfide derivatives}

The experiments in this study were modified based on the method described by Xu et al. (2001). For each reaction, $32.8 \pm 4.1 \mu \mathrm{g}$ of LCAs from Lake BrayaSø were dissolved in $50 \mu \mathrm{L}$ of hexane. To initiate the reaction, a $40 \mu \mathrm{L}$ iodine solution with variable concentrations (15 to 225 $\mathrm{mg} \mathrm{I}_{2} / 1 \mathrm{~mL}$ of $\mathrm{Et}_{2} \mathrm{O}$ ) and $200 \mu \mathrm{L}$ of DMDS were added to the dissolved LCAs. After briefly flushing with $\mathrm{N}_{2}$ gas for 30 seconds, the reaction mixture was capped and held at a constant temperature while being stirred at $375 \mathrm{rpm}$ for a specified time period. The reaction was stopped using $5 \%$ sodium thiosulfate in deionized water, which was then diluted with hexane. The organic phase was transferred to a clean vial and anhydrous sodium sulfate was added, and then allowed to sit for 30 seconds. The resulting reaction mixture was isolated and evaporated to dryness. Samples were quantified using a GC-FID with 18-pentatriacontanone as an internal standard. For each of the samples, the percent yield was calculated relative to the initial amount of LCAs used for the reaction.

To determine how we should modify the procedure proposed by Xu et al. (2001), we performed an initial series of reactions that varied time, temperature, stirring/non-stirring, iodine amounts, and solvents. These results indicated that the duration of the reaction and the temperature at which it was held were the primary factors controlling the reaction yield. In Xu et al. (2001), the reaction mixture was heated for 20 hours at $40{ }^{\circ} \mathrm{C}$. In our experiments, we used a design of experiment (DoE) framework (Telford, 2007; Moseley and Murray, 2014) to map out a 2-factor, 3-level design for systematic time and temperature experiments with temperatures ranging from $0-75{ }^{\circ} \mathrm{C}$ and reaction times from 10 mins to 24 hours (Supplementary Table S1). We found that iodine is a secondary factor influencing the product yield. After optimizing the 
time and temperature conditions, we used an additional DoE framework with a 3-factor, 3-level design to maximize time, temperature, and the amount of iodine.

To avoid degradation of DMDS adducts and to ensure that no other reactions occurred, all products were analyzed immediately after the reactions were performed or blown down with $\mathrm{N}_{2}$ gas and kept frozen until the samples were analyzed. Additional tests were done to track the degradation of DMDS adducts after samples were blown down with $\mathrm{N}_{2}$ gas and kept frozen overnight. These experiments showed that $58.4 \pm 3.0 \%$ of the products were lost after the samples were measured, stored in a freezer overnight, and then re-measured on the GC-FID after two days.

\subsection{Analysis of alkenone derivatives by GC-FID and GC-MS}

Alkenone dimethyl disulfide adducts were analyzed using a GC-FID (Agilent 6890N) and GC-MS (Agilent 6890N GC, Agilent 5973N quadrupole mass spectrometer) with a VF200ms capillary column (30 m for GC-FID and $60 \mathrm{~m}$ for GC-MS, $250 \mu \mathrm{m}$ i.d., $0.10 \mu \mathrm{m}$ film thickness) with the method described by Longo et al. (2013). Samples were injected onto the column using a split/splitless injector (splitless mode) with the injector port and transfer line temperature set to $330{ }^{\circ} \mathrm{C}$. The carrier gas $(\mathrm{He})$ was held at a constant flow rate of $1.3 \mathrm{~mL} / \mathrm{min}$. The initial oven temperature was set to $75^{\circ} \mathrm{C}$ and held for $1 \mathrm{~min}$, then increased to $320^{\circ} \mathrm{C}$ at 10 ${ }^{\circ} \mathrm{C} / \mathrm{min}$ and held for 30 mins. The mass spectrometer was operated in EI mode $(70 \mathrm{eV})$ with a scan range of $50-750 \mathrm{~m} / \mathrm{z}$. Gas chromatograms for the GC-FID were analyzed by first establishing a baseline for each cluster of identifiable peaks (i.e., $\mathrm{C}_{37} \mathrm{Me}, \mathrm{C}_{38} \mathrm{Et}, \mathrm{C}_{38} \mathrm{Me}$, and $\mathrm{C}_{39} \mathrm{Et}$ ) for the original alkenone and the visible DMDS adducts. GC-FID peaks were then 
quantified in clusters by summing the areas under the identified peaks to obtain totals for the original alkenones and DMDS adducts. All GC-FID and GC-MS data was exported from Agilent ChemStation for further processing in MATLAB (R2016a) using custom scripts and data processing routines available at https://www.github.com/chemplexity/chromatography. 


\section{Results and Discussion}

\subsection{Key variables affecting alkenone dimethyl disulfide reactions}

An initial set of experimental trials identified three key factors affecting DMDS-1 yields: reaction time, temperature, and iodine amount. In our first assessment, we compared the yield of DMDS- 1 at 20,50 , and $75{ }^{\circ} \mathrm{C}$ for a reaction time of 210 mins. At $20^{\circ} \mathrm{C}$, the products included DMDS binding to multiple double bonds (for consistency with DMDS-1, we designate those with two double bonds adducted by DMDS as DMDS-2, and similarly three double bonds as DMDS-3, etc.; Fig. 1). At $50{ }^{\circ} \mathrm{C}$, DMDS-1 products were still visible on the GC-FID chromatograms, but with low yields (6.0\% at $30 \mathrm{mins}, 1.0 \%$ at $120 \mathrm{mins}$, and $0.3 \%$ at $210 \mathrm{mins}$ ). A further increase in reaction temperature to $75^{\circ} \mathrm{C}$, led to a further decline in yield and even the complete absence of DMDS adducts from the gas chromatograms (1.6\% at 30 mins, and $0.0 \%$ at 120 and 210 mins). These results suggest that the reaction yields for DMDS- 1 were higher at lower temperatures. Most literature reports using DMDS adduction carried out reactions at 40 $50{ }^{\circ} \mathrm{C}$ (Buser et al., 1983; Leonhardt and DeVilbiss, 1985; Vincenti et al., 1987; Pepe et al., 1997; Xu et al., 2001; Méjanelle et al., 2002; van Soelen et al., 2014; Dillon et al., 2016; Zheng et al., 2016), although others reported performing DMDS reactions at a temperature of $70{ }^{\circ} \mathrm{C}$ (Zhao et al., 2014). Our initial results thus suggest lower temperature could increase the DMDS1 product yields. This is readily explained by the fact that DMDS- 1 is a transient product in the reaction between DMDS and alkenones with multiple double bonds: lower temperatures slow down the overall reaction and reduce adduction onto multiple double bonds. 
We also found that prolonged reaction times (e.g., overnight) resulted in a significant loss or even the complete disappearance of DMDS-1 adducts and the original alkenones. For example, when we performed the reaction at $40{ }^{\circ} \mathrm{C}$ for 22 hours, neither the DMDS adducts nor the original alkenones were visible on the gas chromatograms. This indicated that reaction time was also critical to maximizing DMDS-1 yield, and that extended reaction times did not always lead to higher product yields.

Altering the amount of iodine (all previous reactions were initiated with $2.4 \mathrm{mg}$ ) used in the reaction, appreciably changed DMDS-1 yields. A reduction in iodine to 1.2 and $0.6 \mathrm{mg}$ decreased yields of DMDS-1 adducts. Conversely, increasing the amount of iodine to 3.0, 4.0, and $6.0 \mathrm{mg}$, led to an increase in product yield. Because the molar ratio of iodine/original alkenone is 138.7 at $2.4 \mathrm{mg} \mathrm{I}_{2}$ and the molar ratio of DMDS/original alkenone is over 30,000 for $200 \mu 1$ DMDS, we can reasonably exclude the possibility that the optimal iodine amount is dictated by the amount of reactant alkenones. It is likely that optimal amount of iodine is mainly determined by the amount of DMDS reagent used.

As part of the initial experiments we also varied the solvents and stirring/no-stirring at constant times and temperatures. In all previous reactions, hexane was used to dissolve the reaction mixture. There was, however, no significant change in yield when hexane was switched to a different solvent (tetrahydrofuran and toluene). Not stirring the reaction while it was held at a constant temperature for an extended period of time led to a significant decrease and even the disappearance of DMDS-1. In contrast, stirring the reaction at $375 \mathrm{rpm}$, as previously described by Francis (1981), greatly increased DMDS adducts.

\subsection{Optimal reaction conditions for dimethyl disulfide adduct formation}


In order to determine the optimal reaction conditions, we used a DoE to first systematically vary the reaction temperature and time followed by an additional DoE where we varied the time, temperature, and iodine amounts. The results for different reaction times, temperatures, and iodine amounts are plotted in Fig. 2. A cubic interpolation was applied to the data in order to map out changes in yield under varying reaction conditions. The experimental temperatures were chosen based on how easy and practical it was to maintain the reaction at the given temperature for an extended period of time. For instance, reactions at $0{ }^{\circ} \mathrm{C}$ were performed in an ice bath, while $20^{\circ} \mathrm{C}$ corresponds to room temperature and experiments at $40{ }^{\circ} \mathrm{C}$ were heated using a hot plate. Reactions at $10{ }^{\circ} \mathrm{C}$ or $-10^{\circ} \mathrm{C}$ could produce appreciable yields, however, these temperatures were not pragmatic for most laboratory set-ups and thus were not considered in this study.

We found that the highest DMDS-1 yields occurred at different times and temperatures when the amount of iodine was changed (Fig. 2). For $2.4 \mathrm{mg}$ of $\mathrm{I}_{2}$ the highest yields occurred at 250 mins $0{ }^{\circ} \mathrm{C}(22.6 \%)$ and $160 \operatorname{mins} 20{ }^{\circ} \mathrm{C}(23.2 \%)$. When $\mathrm{I}_{2}$ was increased to $3 \mathrm{mg}$, the optima occurred at: $220 \operatorname{mins} 0{ }^{\circ} \mathrm{C}(19.8 \%), 250 \operatorname{mins} 0{ }^{\circ} \mathrm{C}(18.2 \%), 280 \operatorname{mins} 0{ }^{\circ} \mathrm{C}(18.5 \%), 310 \operatorname{mins} 0$ ${ }^{\circ} \mathrm{C}(21.2 \%)$. For $4 \mathrm{mg} \mathrm{I}_{2}$ the DMDS-1 yield peaked at 160 and 250 mins $0{ }^{\circ} \mathrm{C}(22.2 \%$ and $21.0 \%$, respectively), and for $6 \mathrm{mg} \mathrm{I}_{2}$ at 120 mins $0{ }^{\circ} \mathrm{C}(19.7 \%)$. Variable yields under different conditions suggest that DMDS adduction is kinetically controlled because our desired product, DMDS-1, is transient between the original alkenones and multiply adducted alkenones. This suggests that any subtle changes in the experimental procedure can lead to significant shifts in DMDS-1 yields. Most samples were analyzed as soon as possible after the reactions were completed, and were kept frozen prior to being analyzed with the GC-FID. However, a more 
detailed analysis is required to determine how quickly samples degrade at room temperature and over the course of a couple hours.

The most consistent and highest yields occur at $0{ }^{\circ} \mathrm{C}$. The results showed that increased amounts of iodine reduced the reaction time. An optimum was also observed at $20{ }^{\circ} \mathrm{C}$ for $2.4 \mathrm{mg}$ of $\mathrm{I}_{2}$. This agreed with the time and temperature DoE: high DMDS-1 yields occurred at low temperatures and long reaction times, and at high temperatures and short reaction times (Supplementary Fig. S2). Based on these results, we hypothesize that higher temperatures and more iodine contribute to increased reaction rates (see sections 3.4 and 3.5).

\subsection{Confirmation of dimethyl disulfide derivatives}

Diagnostic mass fragments obtained by GC-MS were used to confirm the identity of DMDS-1 adducts. The mass spectra of all DMDS-1 peaks exhibited characteristically low molecular ion $\left(\mathrm{M}^{+}\right.$) peaks (Fig. 3). The mass spectra of the DMDS derivatives show fragment ions associated with the loss of $\mathrm{SCH}_{3}\left(\mathrm{M}^{+}-47\right), \mathrm{CH}_{3} \mathrm{~S}=\mathrm{CH}_{2}^{+}\left(\mathrm{M}^{+}-61\right)$, and $\mathrm{CH}_{3} \mathrm{SSCH}_{3}\left(\mathrm{M}^{+}-\right.$ 94). The spectra contain peaks that indicate fragmentation at the various carbon-carbon double bonds, for example, with the $\mathrm{C}_{37: 4 \mathrm{Me}}$ alkenone, the double bond located at the $\Delta^{7}$ position was determined by locating the ketone containing fragment $(173 \mathrm{~m} / \mathrm{z})$, and the corresponding alkene fragment $(447 \mathrm{~m} / \mathrm{z})$. In this case, DMDS-1 adducts for each of the four double bonds on the $\mathrm{C}_{37: 4}$ Me alkenones were not resolved by GC-MS under the experimental condition. Hence, the mass spectrum in Fig. 3 represents combined mass fragments from all four possible DMDS-1 adducts. Fortunately, determining the position of any specific double bonds on the alkenone only requires identification of two complementary molecular masses on the mass spectra (Fig. 3). Therefore, 
co-elution of DMDS-1 adducts for a given alkenone on the GC-MS does not pose a significant problem for conclusive structure elucidation. The entire suite of DMDS alkenone homologues (i.e., $\mathrm{C}_{37 \mathrm{Me}}, \mathrm{C}_{38 \mathrm{Et}}, \mathrm{C}_{38 \mathrm{Me}}$, and $\mathrm{C}_{39 \mathrm{Me}}$ ) exhibited the same fragmentation patterns described above (for more mass spectra see Supplementary Fig. S4 - S11 and Supplementary Information for Dillon et al. (2016)).

\subsection{Influence of time and temperature on reaction rates}

In the initial time and temperature experiments, a potential inverse relationship was observed between time and temperature: local optima for DMDS-1 yields was observed at 10 mins at $40{ }^{\circ} \mathrm{C}, 160$ mins at $20^{\circ} \mathrm{C}$, and 250 mins at $0{ }^{\circ} \mathrm{C}$. This could indicate that the reaction rate increased at higher temperatures. We looked at how each of these reactions evolved over time at a specified temperature, which showed that the highest DMDS-1 yields occurred just as DMDS0 significantly decreased and DMDS-2 adducts started to form (Supplementary Fig. S2).

We propose that the peak in DMDS-1 occurred just as excess DMDS began to react with additional alkenone double bonds to form DMDS-2 adducts. Similarly, if the reaction was not stopped at the right time, any excess DMDS would continue to react with available alkenone double bonds to form DMDS-3 and DMDS-4 adducts. This was validated by the presence of DMDS-3 adducts when reactions were allowed to run for longer periods of time (Supplementary Fig. S1). DMDS-4 adducts, however, were not visible on the GC due to their high molecular mass. The relationship between time and temperature for optimal DMDS-1 product yields indicated that the rate at which DMDS bond to alkenone double bonds increased at higher 
temperatures. Conversely, the rate of DMDS bonding to alkenone double bonds decreased at lower temperatures.

The reactions performed by Yamamoto et al. (1991) with methyl lineoleate were in agreement with our experiments: the authors observed that DMDS-1 adduct formation peaked at shorter times for $35^{\circ} \mathrm{C}$. For instance, the authors found that the initial methyl lineoleate concentrations decreased rapidly from 0 to 15 mins as DMDS-1 adducts began to form. Similarly, the initial alkenones and DMDS-1 adducts in our reactions decreased between 0 and 60 mins when reactions were performed at $40{ }^{\circ} \mathrm{C}$ (Supplementary Fig. S2).

The relationship between time and temperature for optimal DMDS-1 adducts indicated that multiple reaction conditions could produce optimal DMDS-1 yields. This agreed with the range of times and temperatures cited by previous papers (Table 1). Each of these methods generated DMDS-1 adduct yields for both fatty acids and alkenones, but with varying yields of DMDS-1 adducts. The optimal time and temperature conditions for DMDS reactions with fatty acids were not addressed in this paper, and may be different from the proposed method for alkenone and DMDS reactions.

\subsection{Influence of iodine on reaction rates}

Iodine was thought to act as a catalyst in the reaction, and had a large influence on DMDS-1 yields. In the initial time and temperature reactions, the amount of iodine $(2.4 \mathrm{mg}) \mathrm{was}$ kept constant. However, additional experiments showed that decreasing the amount of iodine led to a decrease in the DMDS-1 yield, and conversely an increase in iodine led to an increase in DMDS-1 adducts. The time and temperature that corresponded with the highest DMDS-1 adduct 
yields varied with the amount of iodine used, such that increased iodine led to shorter reaction times at lower temperatures (Fig. 2). For instance, a peak in DMDS- 1 occurred at 250 mins $0{ }^{\circ} \mathrm{C}$ for $2.4 \mathrm{mg} \mathrm{I}_{2}(22.6 \%)$. When $\mathrm{I}_{2}$ was increased to $6 \mathrm{mg}$, DMDS-1 peaked at $120 \mathrm{mins} 0{ }^{\circ} \mathrm{C}$ (19.7\%). Based on these results, we propose that additional iodine increased the reaction rate and thus the formation of DMDS adducts. If a large excess of iodine was present in the reaction, however, iodine had the potential to further catalyze the formation of DMDS-2, DMDS-3, and DMDS-4 adducts. This could make it more difficult to stop the reaction at the appropriate time for the optimal DMDS-1 adducts, and could lead to variable results. Based on our experimental results, the highest DMDS-1 yields occurred for $2.4 \mathrm{mg} \mathrm{I}_{2}$ at $250 \mathrm{mins} 0{ }^{\circ} \mathrm{C}$ and $160 \mathrm{mins} 20{ }^{\circ} \mathrm{C}$, and for $4 \mathrm{mg} \mathrm{I}_{2}$ at 160 mins $0{ }^{\circ} \mathrm{C}$ and 250 mins $0{ }^{\circ} \mathrm{C}$ (Fig. 2).

\subsection{Proposed dimethyl disulfide reaction mechanism}

Aspects of the reaction mechanism for DMDS adduct formation are not well understood. Previous studies for fatty acid DMDS derivatization determined that the reaction is antistereospecific (Buser et al., 1983) and in di-unsaturated fatty acids, DMDS addition is catalyzed by iodine and forms a sulphonium ring intermediate (Vincenti et al., 1987). The reaction mechanism proposed by Vincenti et al. (1987), was mainly relevant to fatty acids with double bonds in the Z-configuration, however, they propose that the mechanism might also hold true for double bonds in the $E$-configuration. A similar mechanism might also be applicable to alkenones, where double bonds are in the $E$-configuration (Rechka and Maxwell, 1988). The $E$ configuration could decrease the rate of DMDS reacting with alkenone double bonds, which would amplify the importance of iodine as a catalyst in the reaction. Alkenone double bonds are 
usually separated by at least three methylene groups (de Leeuw et al., 1980; López and Grimalt, 2004; Rontani et al., 2006; Dillon et al., 2016), which would reduce the likelihood of forming cyclization products during the DMDS reaction. In comparison, when fatty acids with multiple conjugated double bonds that have one, two, or three methylene-interruptions were reacted with DMDS, they were prone to form cyclized products (Christie, 1998; Méjanelle et al., 2002; Zhu, 2003) and complicated double bond position identification. Xu et al. (2001) described one instance where three methylene interrupted alkenone cyclization occurred following a reaction of Black Sea alkenones with DMDS at $40{ }^{\circ} \mathrm{C}$ for 20 hours. As shown in this paper and in our recent study, Zheng et al. (2016), a reduction in the reaction time can generate DMDS-1 adducts without obvious cyclization products and facilitate the identification of double bond positions.

To account for the major controls on DMDS adduct formation we propose a potential reaction mechanism that complements the previous mechanism described by Vincenti et al. (1987), but with an additional iodonium complex that precedes DMDS addition (Fig. 4). The reaction is initiated by an iodine catalyst that forms an iodonium complex with a carbon-carbon double bond. The remaining iodide anion then undergoes a substitution reaction with DMDS that generates a methanethiolate anion and thiomethyl iodine. The methanethiolate anion adds via anti-addition to the iodonium ion, which then forms a three-membered sulphonium ring intermediate. The iodide anion regenerates the iodine catalyst and forms a second methanethiolate anion. The methanethiolate anion adds via anti-addition to the three-membered ring and thereby forms the observed DMDS adduct.

\subsection{Mass balance for the DMDS reaction products with alkenones}


At optimal conditions, the reactions in this study produced DMDS-1 adduct yields of $20.4 \pm 1.8 \%$. The product yield did not, however, account for the $80 \%$ loss of the original sample. For instance, when reactions were performed with $2.4 \mathrm{mg} \mathrm{I}_{2}$ for 250 mins at $0{ }^{\circ} \mathrm{C}$ the following adducts were observed: DMDS-0 42.0\%, DMDS-1 22.6\%, and DMDS-2 1.7\%. This accounted for $66.3 \%$ of the original alkenones, but did not account for the remaining $33.7 \%$ that was lost during the reaction.

To explain this, we propose three possible scenarios that could lead to sample loss (Fig. 5; Supplementary Fig. S3): 1) The reaction formed additional DMDS-3 and DMDS-4 adducts, which were not visible on the chromatographs due to their high molecular mass and low peak intensities. 2) Some of the initial alkenones and products were degraded prior to running the samples on the GC-FID; and/or 3) additional reactions, such as polymerization through polysulfide linkages, occurred between alkenone DMDS adducts. Further and more in-depth studies are required to test these hypotheses. 


\section{Conclusions}

In this study, we showed that DMDS adduction onto alkenones is a kinetically controlled reaction initiated by an iodine catalyst. At lower temperatures, we were able to reduce the reaction rate and control the production of DMDS- 1 adducts. We found that DMDS- 1 adducts were transient alkenone products with DMDS bound to only one alkenone double bond, which was ideal for identifying double bond positions using the GC-MS. To optimize the yield of DMDS-1 we used a DoE set up to target the best reaction temperature, reaction duration, and amount of catalyst needed to initiate DMDS binding to alkenone double bonds. Most previous published work on alkenone double bond derivatization techniques attempted to derivatize all double bonds at once (Xu et al., 2001; van Soelen et al., 2014). This often resulted in high molecular weight products that were unsuited for GC-MS analysis.

We demonstrated that the optimal conditions for consistent alkenone DMDS-1 adduct formation occurred at $0{ }^{\circ} \mathrm{C}$ with yields of $20.4 \pm 1.8 \%$. The reaction time also varied depending on the amount of iodine used to catalyze DMDS bonding to alkenone double bonds. The overall highest yields were observed when an iodine amount of $2.4 \mathrm{mg}$ was used and the reaction was run for 160 mins at $20{ }^{\circ} \mathrm{C}(23.2 \%)$ and 250 mins at $0{ }^{\circ} \mathrm{C}(22.6 \%)$, and at $4 \mathrm{mg} \mathrm{I}_{2}$ for 160 and 250 mins $0{ }^{\circ} \mathrm{C}(22.2 \%$ and $21.0 \%$, respectively). Reactions at higher temperatures, such as 20 or 40 ${ }^{\circ} \mathrm{C}$, also generated high DMDS adduct yields when performed for shorter time periods and with lower iodine amounts. DMDS adduct yield at higher temperatures, however, was generally more variable than reactions performed at $0{ }^{\circ} \mathrm{C}$. At these high temperatures it could be more difficult to capture the point of optimal yield for transient DMDS-1 products, especially because any subtle changes in experimental conditions could lead to a shift in the peak and result in sample 
loss. We also observed sample degradation after we left samples frozen for two days. Lower temperatures, reaction times of 160 to 250 mins, and $\mathrm{I}_{2}$ amounts of 2.4 to $4 \mathrm{mg}$ guarantee DMDS-1 adduct formation that can be applied to alkenone double bond identification. We therefore recommend performing DMDS derivatization with $4 \mathrm{mg}$ of $\mathrm{I}_{2}, 200 \mu \mathrm{DMDS}$ at $0^{\circ} \mathrm{C}$ for 160 mins. 


\section{Acknowledgements}

We thank R. Tarozo for laboratory and technical support. This work was supported by a National Science Foundation awards to Y.H. [EAR-1122749, PLR-1503846; EAR-1502455]. 


\section{References}

Brassell, S.C., Eglinton, G., Marlowe, I.T., Pflaumann, U., Sarnthein, M., 1986. Molecular Stratigraphy: A new tool for climatic assessment. Nature 320, 264-265.

Buser, H.R., Arn, H., Guerin, P., Rauscher, S., 1983. Determination of double bond position in mono-unsaturated acetates by mass spectrometry of dimethyl disulfide adducts. Analytical Chemistry 55, 818-822.

Carballeira, N.M., Shalabi, F., Cruz, C., 1994. Thietane, tetrahydrothiophene and tetrahydrothiopyran formation in reaction of methylene-interrupted dienoates with dimethyl disulfide. Tetrahedron Letters 35, 5575-5578.

Christie, W.W., 1998. Gas chromatography-mass spectrometry methods for structural analysis of fatty acids. Lipids 33, 343-353.

Conte, M.H., Thompson, A., Lesley, D., Harris, R.P., 1998. Genetic and physiological influences on the alkenone/alkenoate versus growth temperature relationship in Emiliania huxleyi and Gephyrocapsa oceanica. Geochimica et Cosmochimica Acta 62, 51-68.

D’Andrea, W.J., Huang, Y., 2005. Long chain alkenones in Greenland lake sediments: Low $\delta^{13} \mathrm{C}$ values and exceptional abundance. Organic Geochemistry 36, 1234-1241.

de Leeuw, J.W., van der Meer, F.W., Rijpstra, W.I.C., Schenck, P.A., 1980. On the occurrence and structural identification of long chain ketones and hydrocarbons in sediments. Physics and Chemistry of the Earth 12, 211-217.

Dillon, J.T., Longo, W.M., Zhang, Y., Torozo, R., Huang, Y., 2016. Identification of double bond positions in isomeric alkenones from a lacustrine haptophyte. Rapid Communications in Mass Spectrometry 30, 112-118.

Dunkelblum, E., Tan, S.H., Silk, P.J., 1985. Double-bond location in monounsaturated fatty 
acids by dimethyl disulfide derivatization and mass spectrometry: Application to analysis of fatty acids in pheromone glands of four lepidoptera. Journal of Chemical Ecology 11, 265277.

Francis, G.W., 1981. Alkylthiolation for the determination of double-bond position in unsaturated fatty acid esters. Chemistry and Physics of Lipids 29, 369-374.

Herbert, T.D., 2006. Alkenone paleotemperature determinations, in: Holland H.D. \& Turekian K.K. (Ed.), The Oceans and Marine Geochemistry. Elsevier, Oxford, pp. 391-432.

Jaraula, C.M.B., Brassell, S.C., Morgan-Kiss, R.M., Doran, P.T., Kenig, F., 2010. Origin and tentative identification of tri to pentaunsaturated ketones in sediments from Lake Fryxell, East Antarctica. Organic Geochemistry 41, 386-397.

Leonhardt, B.A., DeVilbiss, E.D., 1985. Separation and double-bond determination on nanogram quantities of aliphatic monounsaturated alcohols, aldehydes and carboxylic acid methyl esters. Journal of Chromatography A 322, 484-490.

Longo, W.M., Dillon, J.T., Tarozo, R., Salacup, J.M., Huang, Y., 2013. Unprecedented separation of long chain alkenones from gas chromatography with a poly(trifluoropropylmethylsiloxane) stationary phase. Organic Geochemistry 65, 94-102.

Longo, W.M., Theroux, S., Giblin, A.E., Zheng, Y., Dillon, J.T., Huang, Y., 2016. Temperature calibration and phylogenetically distinct distributions for freshwater alkenones: Evidence from northern Alaskan lakes. Geochimica et Cosmochimica Acta 180, 177-196.

López, J.F., Grimalt, J.O., 2004. Phenyl- and cyclopentylimino derivatization for double bond location in unsaturated $\mathrm{C}_{37}-\mathrm{C}_{40}$ alkenones by GC-MS. Journal of the American Society for Mass Spectrometry 15, 1161-1172.

López, J.F., Grimalt, J.O., 2006. Reassessment of the structural composition of the alkenone 
distributions in natural environments using an improved method for double bond location based on GC-MS analysis of cyclopropylimines. Journal of the American Society for Mass Spectrometry $17,710-720$.

Méjanelle, L., Laureillard, J., Saliot, A., 2002. Novel marine flagellate fatty acid: Structural elucidation by GC-MS analysis of DMOX derivatives and DMDS adducts. Journal of Microbiological Methods 48, 221-237.

Moseley, J.D., Murray, P.M., 2014. Ligand and solvent selection in challenging catalytic reactions. Journal of Chemical Technology and Biotechnology 89, 623-632.

Müller, P.J., Čepek, M., Ruhland, G., Schneider, R.R., 1997. Alkenone and coccolithophorid species changes in late Quaternary sediments from the Walvis Ridge: Implications for the alkenone paleotemperature method. Palaeogeography, Palaeoclimatology, Palaeoecology $135,71-96$.

Nichols, P.D., Guckert, G.B., White, D.C., 1986. Determination of monounsaturated doublebond fatty acid position and geometry for microbial cultures and complex consortia by capillary GC-MS of their dimethyl disulphide adducts. Journal of Microbiological Methods $5,49-55$.

Pepe, C., Sayer, H., Dagaut, J., Couffignal, R., 1997. Determination of double bond positions in triunsaturated compounds by means of gas chromatography/mass spectrometry of dimethyl disulfide derivatives. Rapid Communications in Mass Spectrometry 11, 919-921.

Prahl, F.G., Wakeham, S.G., 1987. Calibration of unsaturation patterns in long-chain ketone compositions for paleotemperature assessment. Nature 330, 367-369.

Prahl, F.G., Muehlhausen, L.A., Zahnle, D.L., 1988. Further evaluation of long-chain alkenones as indicators of paleoceanographic conditions. Geochimica et Cosmochimica Acta 52, 
$2303-2310$.

Prahl, F.G., Rontani, J.F., Volkman, J.K., Sparrow, M.A., Royer, I.M., 2006. Unusual C 35 and $\mathrm{C}_{36}$ alkenones in a paleoceanographic benchmark strain of Emiliania huxleyi. Geochimica et Cosmochimica Acta 70, 2856-2867.

Rechka, J.A., Maxwell, J.R., 1988. Characterisation of alkenone temperature indicators in sediments and organisms. Organic Geochemistry 13, 727-734.

Rontani, J.F., Marchand, D., Volkman, J.K., 2001. $\mathrm{NaBH}_{4}$ reduction of alkenones to the corresponding alkenols: A useful tool for their characterisation in natural samples. Organic Geochemistry 32, 1329-1341.

Rontani, J.F., Bonin, P., Jameson, I., Volkman, J.K., 2005. Degradation of alkenones and related compounds during oxic and anoxic incubation of the marine haptophyte Emiliania huxleyi with bacterial consortia isolated from microbial mats from the Camargue, France. Organic Geochemistry 36, 603-618.

Rontani, J.F., Prahl, F.G., Volkman, J.K., 2006. Re-examination of the double bond positions in alkenones and derivatives: Biosynthetic implications. Journal of Phycology 42, 800-813.

Scribe, P., Guezennec, J., Dagaut, J., 1988. Identification of the position and the stereochemistry of the double bond in monounsaturated fatty acid methyl esters by gas chromatography/mass spectrometry of dimethyl disulfide derivatives. Analytical Chemistry $60,928-931$.

Shibahara, A., Yamamoto, K., Nakayama, T., Kajimoto, G., 1985. Rapid determination of double bond positions in monounsaturated fatty acids by GC-MS and its application to fatty acid analysis. Journal of Japan Oil Chemists' Society 34, 618-625.

Shibahara, A., Yamamoto, K., Kinoshita, A., Anderson, B.L., 2008. An improved method for 
preparing dimethyl disulfide adducts for GC/MS analysis. Journal of the American Oil Chemists' Society 85, 93-94.

Telford, J., 2007. A brief introduction to design of experiments. Johns Hopkins Applied Physics Laboratory Technical Digest 27, 224-232.

Theroux, S., D’Andrea, W.J., Toney, J., Amaral-Zettler, L., Huang, Y., 2010. Phylogenetic diversity and evolutionary relatedness of alkenone-producing haptophyte algae in lakes: Implications for continental paleotemperature reconstructions. Earth and Planetary Science Letters 300, 311-320.

Urbanová, K., Halík, J., Hovorka, O., Kindl, J., Valterová, I., 2004. Marking pheromones of the cuckoo bumblebee males (Hymenoptera, Apoidea, Bombus Latreille): Compositions of labial gland secretions of six species found in the Czech Republic. Biochemical Systematics and Ecology 32, 1025-1045.

van Soelen, E.E., Lammers, J.M., Eglinton, T.I., Sinninghe Damsté, J.S., Reichart, G.J., 2014. Unusual $\mathrm{C}_{35}$ to $\mathrm{C}_{38}$ alkenones in mid-Holocene sediments from a restricted estuary (Charlotte Harbor, Florida). Organic Geochemistry 70, 20-28.

Vincenti, M., Guglielmetti, G., Cassani, G., Tonini, C., 1987. Determination of double bond position in diunsaturated compounds by mass spectrometry of dimethyl disulfide derivatives. Analytical Chemistry 59, 694-699.

Volkman, J.K., Eglinton, G., Corner, E.D.S., Sargent, J.R., 1980. Novel unsaturated straightchain $\mathrm{C}_{37}-\mathrm{C}_{39}$ methyl and ethyl ketones in marine sediments and a coccolithophore Emiliania huxleyi. Physics and Chemistry of the Earth 12, 219-227.

Xu, L., Reddy, C.M., Farrington, J.W., Frysinger, G.S., Gaines, R.B., Johnson, C.G., Nelson, R.K., Eglinton, T.I., 2001. Identification of a novel alkenone in Black Sea sediments. 
Organic Geochemistry 32, 633-645.

Yamamoto, K., Shibahara, A., Nakayama, T., Kajimoto, G., 1991. Determination of double-bond positions in methylene-interrupted dienoic fatty acids by GC-MS as their dimethyl disulfide adducts. Chemistry and Physics of Lipids 60, 39-50.

Yamamoto, M., Ficken, K., Baas, M., Bosch, H.-J., de Leeuw, J.W., 1996. Molecular palaeontology of the earliest Danian at Geulhemmerberg (the Netherlands). Geologie en Mijnbouw 75, 255-267.

Zhao, J., An, C., Longo, W.M., Dillon, J.T., Zhao, Y., Shi, C., Chen, Y., Huang, Y., 2014. Occurrence of extended chain length $\mathrm{C}_{41}$ and $\mathrm{C}_{42}$ alkenones in hypersaline lakes. Organic Geochemistry 75, 48-53.

Zheng, Y., Huang, Y., Andersen, R.A., Amaral-Zettler, L.A., 2015. Excluding the di-unsaturated alkenone in the $\mathrm{U}_{37}^{\mathrm{K}}$ index strengthens temperature correlation for the common lacustrine and brackish-water haptophytes. Geochimica Cosmochimica Acta 175, 36-46.

Zheng, Y., Dillon, J.T., Zhang, Y., Huang, Y., 2016. Discovery of alkenones with variable methylene interrupted double bonds: Implications for the biosynthetic pathway. Journal of Phycology 52, 1037-1050.

Zhu, L. Investigating the biosynthesis of polyacetylenes: Synthesis of deuterated linoleic acids \& mechanism studies of DMDS addition to 1,4-enynes. Ph.D. Dissertation, Miami University, Oxford, OH, 2003.

Zink, K.-G., Leythaeuser, D., Melkonian, M., Schwark, L., 2001. Temperature dependency of long-chain alkenones in recent to fossil limnic sediments and in lake waters. Geochimica et Cosmochimica Acta 65, 253-265. 


\begin{tabular}{|c|c|c|c|c|c|}
\hline Compounds & DMDS volume $(\mu \mathrm{L})$ & Time (h) & Temperature $\left({ }^{\circ} \mathbf{C}\right)$ & $\mathbf{I}_{2}(\mathrm{mg})$ & Study \\
\hline $\begin{array}{l}\text { Unsaturated fatty acid } \\
\text { esters }\end{array}$ & & 24 & $20^{\dagger}$ & 0.1 & Francis $(1981)^{\ddagger}$ \\
\hline $\begin{array}{l}\text { Mono-unsaturated } \\
\text { acetates }\end{array}$ & 50 & $12^{*}$ & 40 & 0.3 & Buser et al. (1983) \\
\hline $\begin{array}{l}\text { Mono-unsaturated fatty } \\
\text { acids }\end{array}$ & $70-100$ & 24 & 40 & & Dunkelblum et al. (1985) \\
\hline $\begin{array}{l}\text { Mono-unsaturated } \\
\text { alcohols, aldehydes, and } \\
\text { methyl esters }\end{array}$ & 100 & 20 & 40 & 1.8 & Leonhardt and DeVilbiss $(1985)^{\ddagger}$ \\
\hline Fatty acid methyl esters & & & 35 & & Shibahara (1985) \\
\hline $\begin{array}{l}\text { Mono-unsaturated fatty } \\
\text { acids }\end{array}$ & 100 & 48 & 50 & & Nichols et al. (1986) \\
\hline $\begin{array}{l}\text { Di-unsaturated } \\
\text { compounds }\end{array}$ & 50 & 40 & 60 & 0.3 & Vincenti et al. (1987) \\
\hline $\begin{array}{l}\text { Mono-unsaturated fatty } \\
\text { acid methyl esters }\end{array}$ & 100 & 48 & 50 & 1.2 & Scribe et al. $(1988)^{\ddagger}$ \\
\hline Dienoic esters & 300 & 0.5 & 35 & 4 & Yamamoto et al. $(1991)^{\ddagger, \S}$ \\
\hline $\begin{array}{l}\text { Tri-unsaturated } \\
\text { compounds: alkatrienes }\end{array}$ & 100 & 48 & 50 & 1.2 & Pepe et al. (1997) \\
\hline $\begin{array}{l}\text { Tri-unsaturated } \\
\text { compounds: alkatrienes }\end{array}$ & 100 & 100 & 50 & 1.2 & Pepe et al. (1997) \\
\hline $\begin{array}{l}\text { Unsaturated aliphatic } \\
\text { compounds }\end{array}$ & & 4 & 20 & 2.4 & Urbanová et al. $(2004)^{\S}$ \\
\hline Fatty acid methyl esters & 100 & & 35 & 1.3 & Shibahara (2008) \\
\hline Alkenones & 100 & 20 & 40 & 1.8 & Xu et al. (2001) \\
\hline Alkenones & & 48 & 50 & & Méjanelle et al. (2002) \\
\hline Alkenones & 100 & 20 & 40 & 1.2 & van Soelen et al. (2014) \\
\hline Alkenones & 100 & 2 & 70 & 3 & Zhao et al. $(2014)^{\S}$ \\
\hline Alkenones & 100 & 2 & 40 & 1.8 & Dillon et al. $(2015)^{\S}$ \\
\hline Alkenones & 200 & 2 & 40 & 2.4 & Zheng et al. $(2016)^{\S}$ \\
\hline
\end{tabular}

* Overnight $=12$ hours

${ }^{\dagger} 20^{\circ} \mathrm{C}=$ Room temperature

$\$$ These methods are commonly cited as references for methods using the DMDS derivatization method.

$\S$ These studies produced mono-DMDS (or DMDS-1) adducts. 
Table 1. A summary of previous studies that used the DMDS optimization method, and the various conditions used to derivatize alkenones and form DMDS adducts. There are many more studies that apply the DMDS derivatization method with small modifications, most of these studies, however, relate to structural identification of fatty acids and are beyond the scope of this paper. 


\section{Figure Legend}

Fig. 1. GC-FID results showing the original (unreacted residual) alkenone, and the DMDS adducts. DMDS-1 represents all of the mono-adducts, while DMDS-2 represents DMDS bound to two different double bonds in the alkenone. Groups of alkenones are noted, and were identified for quantification purposes. The DMDS-1 peaks are split into multiple peaks based on the number of double bonds. Relative to the unreacted alkenones, the peak height might appear lower than the actual quantities that were determined using the peak area.

Fig. 2. Contour plots for DMDS-1 yields obtained with varying amounts of iodine, time, and temperature. For $\mathrm{I}_{2} 2.4 \mathrm{mg}$ the optimal conditions occur at: $250 \mathrm{~min} 0{ }^{\circ} \mathrm{C}(22.6 \%)$ and $160 \mathrm{~min}$ $20{ }^{\circ} \mathrm{C}(23.2 \%)$. At $\mathrm{I}_{2} 3 \mathrm{mg} \mathrm{Et} 2 \mathrm{O}$ the optimal conditions occur at: $220 \mathrm{~min} 0{ }^{\circ} \mathrm{C}(19.8 \%), 250 \mathrm{~min}$ $0{ }^{\circ} \mathrm{C}(18.2 \%), 280 \min 0{ }^{\circ} \mathrm{C}(18.5 \%), 310 \min 0{ }^{\circ} \mathrm{C}(21.2 \%)$. The DMDS-1 yield peaks for $\mathrm{I}_{2} 4$ $\operatorname{mg~Et}{ }_{2} \mathrm{O}$ at $160 \min 0{ }^{\circ} \mathrm{C}(22.2 \%)$ and $250 \min 0{ }^{\circ} \mathrm{C}(21.0 \%)$. Finally, for $\mathrm{I}_{2} 6 \mathrm{mg}$ the DMDS-1 adducts peaked at $120 \min 0{ }^{\circ} \mathrm{C}(19.7 \%)$. The low points between temperatures of 0 and $20{ }^{\circ} \mathrm{C}$ and the lack of data below $0{ }^{\circ} \mathrm{C}$ result from a lack of data. Reactions at these conditions were considered difficult and impractical to maintain, and thus were not considered in this paper.

Fig. 3. An example of mass spectra showing the characteristic mass fragments for the $C_{37: 4 \mathrm{Me}}$ alkenone with DMDS binding. More mass spectra for alkenone DMDS-1 products can be found at Dillon et al. (2016). 
Fig. 4. Proposed mechanism where the iodine catalyst forms an iodinium complex and generates thiomethyl anions which add via anti-addition to the alkene with a three-membered ring intermediate.

Fig. 5. Potential reactions that the original alkenones can undergo when exposed to DMDS and an iodine catalyst. After the DMDS-1 adducts are formed, the products can (1) react with DMDS to form DMDS adducts, (2) undergo side reactions or product degradation, or (3) form intermolecular linkages with other DMDS adducts. 


\section{DMDS-1}

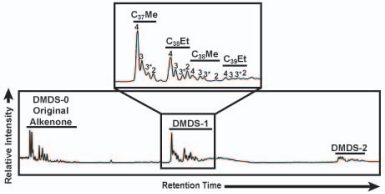


DMDS-1 Yields
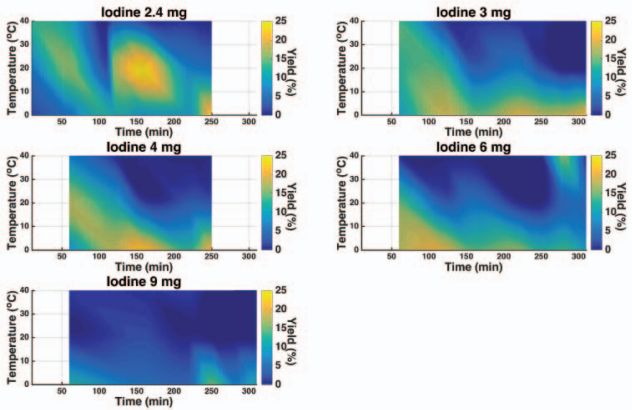

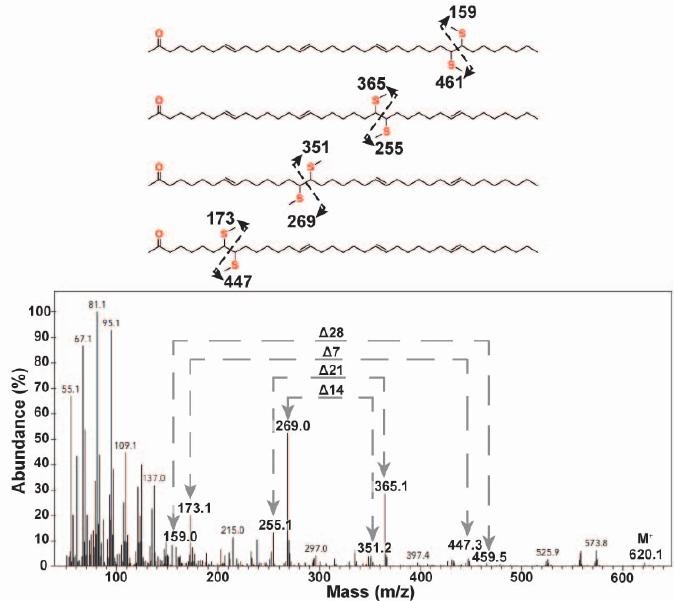


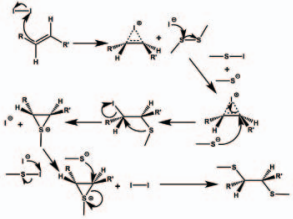




\section{Alkenones}

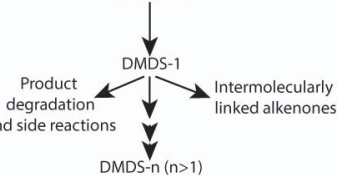




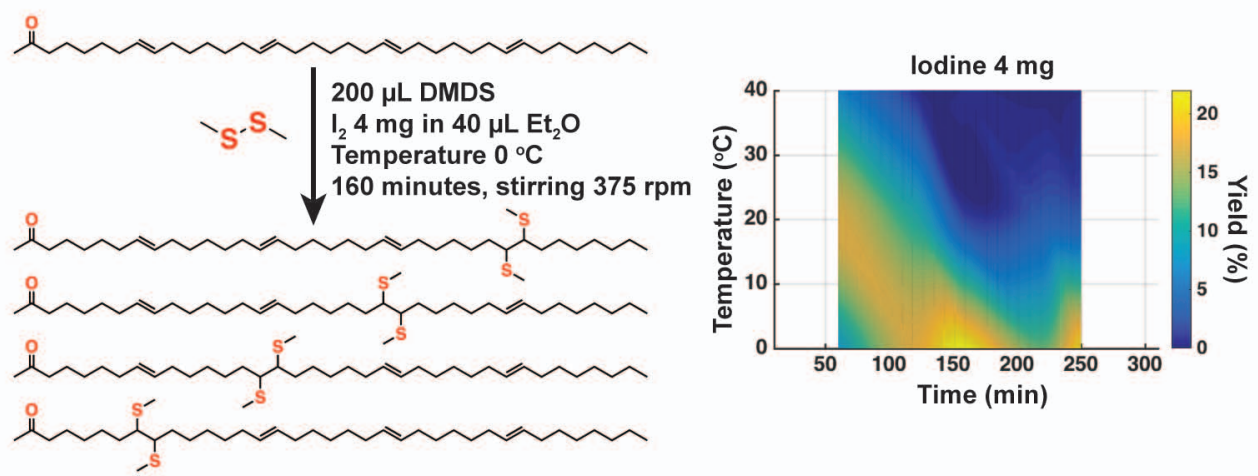

